\title{
Influence of $\boldsymbol{B}_{2}$-adrenoceptor gene polymorphisms on diet-induced thermogenesis
}

\author{
J. M. Oomen ${ }^{1}$, P. M. C. M. Waijers ${ }^{2}$, C. van Rossum², B. Hoebee ${ }^{3}$, W. H. M. Saris ${ }^{1}$ and M. A. van Baak ${ }^{1}$ \\ ${ }^{1}$ Department of Human Biology/NUTRIM, Maastricht University, Maastricht, The Netherlands \\ ${ }^{2}$ Centre for Nutrition and Health and \\ ${ }^{3}$ Laboratory of Toxicology, Pathology and Genetics, National Institute for Public Health and the Environment, Bilthoven, The Netherlands
}

(Received 21 October 2004 - Revised 31 March 2005 - Accepted 9 May 2005)

\begin{abstract}
The sympathetic nervous system is involved in the control of energy metabolism and expenditure. Diet-induced thermogenesis is mediated partly by the $\beta$ adrenergic component of this system. The aim of the present study was to investigate the role of genetic variation in the $\beta_{2}$-adrenoceptor in diet-induced thermogenesis. Data from twenty-four subjects (fourteen men and ten women; BMI 26.7 (SEM 0.8) kg/m² age 45.2(SEM1.4) years) with different polymorphisms of the $\beta_{2}$-adrenoceptor at codon 16 (Gly16Gly, Gly16Arg or Arg16Arg) were recruited for this study. Subjects were given a high-carbohydrate liquid meal, and the energy expenditure, respiratory exchange ratio, and plasma concentrations of NEFA, glycerol, glucose, insulin and catecholamines were measured before and over $4 \mathrm{~h}$ after the meal. The AUC of energy expenditure (diet-induced thermogenesis) was not significantly different between polymorphism groups, nor was the response of any of the other measured variables to the meal. In a multiple regression model, the only variable that explained a significant proportion (32\%) of the variation in diet-induced thermogenesis was the increase in plasma adrenaline in response to the meal $(P<0 \cdot 05)$. The $\beta_{2^{-}}$ adrenoceptor codon 16 polymorphisms did not contribute significantly. In conclusion, an independent contribution of the codon 16 polymorphism of the $\beta_{2^{-}}$ adrenoceptor gene to the variation in thermogenic response to a high-carbohydrate meal could not be demonstrated. The interindividual variation in thermogenic response to the meal was correlated with variations in the plasma adrenaline response to the meal.
\end{abstract}

$B_{2}$-Adrenoceptor polymorphisms: Diet-induced thermogenesis: Catecholamines

Energy expenditure (EE) is an important factor in body-weight regulation. Diet-induced thermogenesis (DIT) is the EE associated with ingestion, absorption and storage of food and accounts for $10-15 \%$ to the total daily EE. DIT shows considerable interindividual variation (Donahoo et al. 2004), and it can be hypothesised that a low DIT contributes to weight gain. Many studies have investigated DIT in obese and lean subjects, but these studies show equivocal results (de Jonge \& Bray, 1997, 2002; Granata \& Brandon, 2002). Nevertheless, when multiple interfering factors are taken into account simultaneously, the evidence for a reduction in DIT in obesity becomes stronger (de Jonge \& Bray, 2002). In addition, several studies show no change in DIT after weight reduction, suggesting that a reduced DIT in obesity is not the consequence of the obese state per se (Bessard et al. 1983; Schutz et al. 1984).

In response to feeding, especially to carbohydrate intake, sympathetic nervous system activity increases (Schwartz et al. 1999; Tappy, 2004). The sympathetic nervous system-mediated thermogenic response is also referred to as facultative thermogenesis (Tappy, 2004). The sympathetic nervous system response is biphasic, with an initial increase in noradrenaline and a delayed adrenaline response (Astrup et al. 1986, 1989). The sympathetic nervous system-mediated component of DIT can be blocked by
B-adrenoceptor antagonists (Astrup et al. 1989; Tappy, 1996), demonstrating the involvement of the $\beta$-adrenergic system.

B-Adrenoceptor genes are suggested to be 'candidate genes' for the development of obesity (Chagnon et al. 2003). Several studies (Echwald et al. 1998; Hellstrom et al. 1999; Kortner et al. 1999; Meirhaeghe et al. 1999; Ukkola et al. 2001; van Rossum et al. 2002; Garenc et al. 2003; Gonzalez Sanchez et al. 2003) have shown an association between polymorphisms at codons 16 and/or 27 of the $\beta_{2}$-adrenoceptor gene and weight gain, obesity or obesity-related phenotypes.

Functional consequences of these polymorphisms with respect to adipocyte lipolysis have also been reported (Large et al. 1997; Eriksson et al. 2004). Large et al. (1997) demonstrated that isolated abdominal subcutaneous fat cells from women homozygous for the arginine 16 (Arg16) polymorphism of the $B_{2}$-adrenoceptor gene had a 5-fold lower sensitivity for lipolysis induced by the $\beta_{2}$-adrenoceptor agonist terbutaline than did fat cells from women who were heterozygous or homozygous for glycine 16 (Gly16), independent of body fat. Eriksson et al. (2004) showed that homozygous haplotypes of the $\beta_{2}$-adrenoceptor gene differed about 250 -fold in their sensitivity to terbutalineinduced lipolysis, the least sensitive haplotype being homozygous for the arginine variant at codon 16 . In addition, we have recently 
reported that the thermogenic response to infusion of the $\beta_{2}$-adrenoceptor agonist salbutamol was blunted in carriers of the Arg16Arg variant of the $\beta_{2}$-adrenoceptor gene compared with Gly16 carriers (Oomen et al. 2005).

We therefore hypothesised that carriers of the Arg16Arg variant of the $B_{2}$-adrenoceptor gene might also have a reduced DIT in response to a high-carbohydrate meal compared with carriers of the Gly16 variant. This might, at least in part, explain the association between this polymorphism and obesity. The present study was designed to test this hypothesis.

\section{Methods}

\section{Subjects}

Twenty-five volunteers (fourteen men and eleven women) participated in the study. They were recruited from an existing cohort in the Maastricht area in The Netherlands that has previously been described (van Rossum et al. 2002). The age of the subjects ranged between 32 and 55 years. They did not use medication at the time of the study or the week before. The study protocol was reviewed and approved by the Ethics Committee of Maastricht University, and all subjects gave written informed consent before participating.

\section{Genotyping of the codon 16 polymorphism of the $\beta_{2}$-adrenoceptor gene}

To genotype the codon 16 polymorphism of the $\beta_{2}$-adrenoceptor gene, genomic DNA was extracted from leucocytes from each individual by digestion with proteinase $\mathrm{K}$ followed by phenolchloroform extraction. Determination of the polymorphism was performed using a PCR-restriction fragment length polymorphism analysis as described before (Large et al. 1997).

\section{Experimental design}

The day preceding the experimental day, subjects consumed a fixed diet provided by the researchers. This diet (energy content $10 \cdot 8(\operatorname{SEM~} 0 \cdot 3) \mathrm{MJ} / \mathrm{d}$ ) consisted of $50 \%$ energy from carbohydrates, $15 \%$ from protein and $35 \%$ from fat, which corresponds to the average macronutrient composition of the Dutch diet. The total amount of energy that each subject received was based on an estimation of resting EE by the Harris-Benedict equation (Harris \& Benedict, 1919) multiplied by an estimation of the subjects' activity level. The activity level was estimated using a short questionnaire. For most subjects, the activity level was set at 1.4 , except when subjects reported to be at least moderately active for more than $3 \mathrm{~h} /$ week, for which a figure of 1.6 was used. Subjects were asked to refrain from unusual or strenuous exercise during the day before the experimental day.

On the experimental day, subjects came to the laboratory in the morning after an overnight fast. They came by car or by bus in order to limit their physical activity before the measurements. Subjects were weighed, and body composition was determined by bio-impedance. Thereafter, a venous catheter was inserted into an antecubital vein for blood sampling. Subjects were then positioned under a ventilated hood in a recumbent position for indirect calorimetry. The indirect calorimetry measurements continued throughout the whole experiment and were interrupted only for the consumption of the meal. Subjects were instructed to limit their movements as much as possible and not to speak during the experiment. They could watch television or a video.

After 30 min rest, baseline measurements were performed: EE was measured over $30 \mathrm{~min}$, and a baseline blood sample was collected at the end. Subjects then received an energy bolus providing $35 \%$ of the energy they had consumed the preceding day (3.71(SEM 0.12) MJ). This test meal consisted of two liquid formulas (total volume 593(SEM 19) $\mathrm{ml}$; Meritene Polvo, Novartis Nutrition and Isostar Long Energy; Novartis Nutrition, Beda, The Netherlands). The macronutrient composition of the test meal was $84 \%$ from carbohydrate, $13 \%$ from protein and $3 \%$ from fat. A high-carbohydrate and high-protein meal is known to stimulate sympathetic nervous system activity (Schwartz et al. 1999). The test meal was consumed within $5 \mathrm{~min}$, and measurements were continued for another $4 \mathrm{~h}$. At 10, 30, 60, 120, 180 and 240 min after the meal, a blood sample was drawn.

\section{Anthropometry and body composition}

Weight was measured to the nearest $100 \mathrm{~g}$ with a digital scale (Seca Delta, Almere, The Netherlands), the subjects wearing clothes but without shoes. Height was known, since it had been measured before in the cohort study (van Rossum et al. 2002). Total body water was measured by single-frequency bioimpedance at $50 \mathrm{kHz}$, using a Xitron 400B bioimpedance analyser (Xitron Technologies Inc., San Diego, CA, USA; van Marken Lichtenbelt et al. 1994). Fat-free mass (FFM) was calculated from weight and total body water using a prediction equation (Lukaski et al. 1986).

\section{Energy expenditure, respiratory exchange ratio}

$\mathrm{V}_{\mathrm{O}_{2}}$ and $\mathrm{CO}_{2}$ production were determined using an open-circuit ventilated-hood system (Omnical, Maastricht, The Netherlands). This system is based on the analysis system for respiration chambers, which has previously been described (Schoffelen et al. 1997). EE was calculated from $\mathrm{V}_{\mathrm{O}_{2}}$ and $\mathrm{CO}_{2}$ production according to the Weir formula (Weir, 1949). Respiratory exchange ratio is the ratio of $\mathrm{CO}_{2}$ production to $\mathrm{V}_{\mathrm{O}_{2}}$.

\section{Analysis of blood samples}

Blood samples for the determination of plasma NEFA, glycerol, glucose and insulin concentrations were collected in sodium EDTA tubes, and samples for plasma noradrenaline and adrenaline concentrations in tubes containing heparin and glutathione $(1.5 \%$ $\mathrm{w} / \mathrm{v})$. Blood samples were immediately centrifuged for $10 \mathrm{~min}$ at $800 \mathrm{~g}$ at $4^{\circ} \mathrm{C}$. Plasma was transferred into test tubes, rapidly frozen in liquid $\mathrm{N}$ and stored at $-80^{\circ} \mathrm{C}$ until further analysis.

Glucose (UniKit III, cat. no. 07367204; Roche, Basel, Switzerland) and NEFA (Wako NEFA-C test kit; Wako Chemicals, Neuss, Germany) were analysed with a COBAS FARA semiautomated analyser (Roche Diagnostica, Basel, Switzerland).

Plasma catecholamine levels (time points 0,120 and $240 \mathrm{~min}$ only) were determined by HPLC according to the method of Alberts et al. (1992) using a ClinPrep kit (Recipe, Munich, Germany). The plasma insulin level was determined with a double antibody RIA (Insulin RIA 100; Linco Research, St Charles, MO, USA). The homeostasis model assessment index, a measure of insulin sensitivity, was calculated according to Matthews et al. (1985) using baseline plasma glucose and insulin levels. 


\section{Statistical methods}

Data are presented as means with their standard errors. For between-group comparisons, EE was adjusted for FFM. Besides absolute values of EE adjusted for FFM, the change in EE from baseline was also expressed as the change relative to the baseline (relative $\mathrm{EE}=\mathrm{EE} /$ baseline EE). DIT was calculated as the AUC of relative and absolute EE over the $4 \mathrm{~h}$ post-meal period and expressed as the relative DIT (relDIT) and absolute DIT (absDIT). Areas under the curve of post-meal changes from baseline were also calculated for glucose, insulin, NEFA, glycerol, noradrenaline and adrenaline concentrations. Changes over time were analysed for the whole group by repeated-measures ANOVA. ANOVA and independent sample $t$ tests were used for comparisons between groups.

Simple regression analysis (Pearson's correlation) was performed with absDIT as the dependent variable and different parameters as the independent variable (energy content of the meal, AUC for glucose, insulin, NEFA, glycerol, noradrenaline and adrenaline, baseline plasma noradrenaline and adrenaline, and homeostasis model assessment index). Multiple stepwise regression analysis, with variables of the simple regression analysis with a value of $P<0.2$ and polymorphism groups as dummy variables, was conducted to estimate the independent contributions of these variables to absDIT. $P<0.05$ was considered to be statistically significant, and all tests were performed as twotailed tests. Statistical analyses were performed with the SPSS 11.0 statistical package (SPSS Inc. Chicago, IL, USA).

\section{Results}

\section{Responses to the meal in the whole group}

One subject could only consume half of the test meal and was therefore excluded from the analysis. Data on twenty-four subjects are reported. Their characteristics are shown in Table 1.

After the test meal, EE increased significantly in the whole group. After $120 \mathrm{~min}$, EE was significantly higher than baseline EE (5.61 (SEM 0.10) $\mathrm{kJ} / \mathrm{min}$ adjusted for FFM $v .4 .63$ (SEM $0.08) \mathrm{kJ} / \mathrm{min}$ adjusted for FFM, respectively; $P<0.001$ ) (Fig. 1). After $240 \mathrm{~min}$, EE was lower (5.34 (SEM 0.09) $\mathrm{kJ} / \mathrm{min}$ ) than at 120 min $(P<0 \cdot 01)$, but it was still significantly higher than the baseline $\mathrm{EE}(P<0.001)$ (Fig 1$)$. The respiratory exchange ratio increased after the meal and remained elevated over the $4 \mathrm{~h}$ post-meal period ( $t=0$ v. $t=240 \mathrm{~min}, P<0 \cdot 001)$ (Fig. 2).

Changes in plasma concentrations of metabolites and insulin are shown in Fig. 3. Plasma glycerol and NEFA levels were significantly lowered over the whole post-meal period $(t=0 \mathrm{v}$. $t=240 \mathrm{~min}, P<0 \cdot 001)$. Plasma glucose concentration was significantly increased at $60 \mathrm{~min}$ compared with the baseline level $(P<0.001)$ and was still higher at 240 min compared with baseline $(P<0 \cdot 05)$. Plasma insulin levels were significantly increased at $60 \mathrm{~min}(P<0.001)$. The insulin concentration increased after the meal and started to decrease 120 min after the meal but was still higher than baseline at $240 \mathrm{~min}(P<0 \cdot 001)$.

Plasma noradrenaline levels (Fig. 4) were significantly elevated at $120 \mathrm{~min}$ and $240 \mathrm{~min}$ after the meal compared with baseline levels $(P<0 \cdot 05)$. Plasma adrenaline levels (Fig. 4) were not significantly different from baseline at $120 \mathrm{~min}(P=0.08)$. At $240 \mathrm{~min}$, however, plasma adrenaline levels were significantly higher than at $120 \mathrm{~min}(P<0 \cdot 01)$.

Baseline values and responses to the meal in the $\beta_{2}$-adrenoceptor codon 16 polymorphism groups

Baseline EE was similar in all polymorphism groups (4.75 (SEM $0 \cdot 11$ ), 4.55 (SEM 0.10) and 4.42 (SEM $0.21(\mathrm{~kJ} / \mathrm{min}$ adjusted for FFM, for Gly16Gly, Gly16Arg and Arg16Arg respectively; NS). There was no significant difference in absDIT $(P=0 \cdot 125$; Fig. 1$)$ or relDIT $(P=0.131)$ between groups (Table 2$)$. In addition, we compared glycine polymorphism carriers (Gly16Arg and Gly16Gly) with Arg16Arg individuals and found a trend $(P=0.06)$ towards Arg16Arg having a higher absDIT and a statistically higher relDIT $(P=0.048)$ compared with Gly polymorphism carriers. None of the other parameters differed statistically significantly between the three groups, either at baseline or with respect to meal-induced changes (Figs. 2-4).

\section{Explanation of energy expenditure response to the meal}

Of all tested variables, the change in EE after the meal (absDIT) was significantly correlated with the change in adrenaline concentration (AUC adrenaline; $P=0.003$ ) and with the energy content of the meal $(P=0.024$; Table 3$)$. In a multiple-regression model, only the AUC of plasma adrenaline level contributed significantly to absDIT

Table 1. Subject characteristics, for the total group and the $\beta_{2}$-adrenoceptor codon 16 variants Gly16Gly, Gly16Arg and Arg16Arg. (Values are means with their standard errors)

\begin{tabular}{|c|c|c|c|c|c|c|c|c|}
\hline & \multicolumn{2}{|c|}{ All } & \multicolumn{2}{|c|}{ Gly16Gly } & \multicolumn{2}{|c|}{ Gly16Arg } & \multicolumn{2}{|c|}{ Arg16Arg } \\
\hline & Mean & SEM & Mean & SEM & Mean & SEM & Mean & SEM \\
\hline \multicolumn{9}{|l|}{$\operatorname{Sex}(M / F)$} \\
\hline Males $(n)$ & \multicolumn{2}{|c|}{14} & \multicolumn{2}{|c|}{7} & \multicolumn{2}{|c|}{3} & \multicolumn{2}{|c|}{4} \\
\hline Females $(n)$ & \multicolumn{2}{|c|}{10} & \multicolumn{2}{|c|}{6} & \multicolumn{2}{|c|}{3} & \multicolumn{2}{|c|}{1} \\
\hline Estimated energy intake (MJ/d) & $10 \cdot 76$ & 0.30 & $10 \cdot 79$ & 0.41 & $10 \cdot 36$ & $0 \cdot 19$ & $11 \cdot 17$ & 0.83 \\
\hline Energy content test meal (MJ) & 3.76 & 0.11 & 3.7 & 0.14 & 3.62 & 0.19 & 3.92 & 0.29 \\
\hline Height (m) & $1 \cdot 75$ & 0.02 & $1 \cdot 76$ & 0.03 & $1 \cdot 71$ & 0.03 & 1.75 & 0.05 \\
\hline Weight (kg) & $81 \cdot 70$ & 3.00 & $81 \cdot 40$ & $4 \cdot 10$ & 80.50 & $3 \cdot 80$ & $84 \cdot 10$ & $9 \cdot 80$ \\
\hline Age (years) & $45 \cdot 20$ & 1.40 & $44 \cdot 00$ & $2 \cdot 10$ & $49 \cdot 50$ & 1.50 & 43.30 & $2 \cdot 40$ \\
\hline BMI $\left(\mathrm{kg} / \mathrm{m}^{2}\right)$ & $26 \cdot 70$ & 0.80 & $26 \cdot 10$ & $1 \cdot 10$ & $27 \cdot 70$ & $1 \cdot 30$ & $27 \cdot 00$ & $2 \cdot 10$ \\
\hline Body fat (\%) & $28 \cdot 90$ & $2 \cdot 00$ & $30 \cdot 70$ & $2 \cdot 70$ & $29 \cdot 60$ & $5 \cdot 10$ & 23.40 & $2 \cdot 20$ \\
\hline Fat-free mass $(\mathrm{kg})$ & $58 \cdot 30$ & $2 \cdot 90$ & $58 \cdot 30$ & $2 \cdot 90$ & $57 \cdot 10$ & $5 \cdot 80$ & $64 \cdot 30$ & $7 \cdot 60$ \\
\hline Resting energy expenditure (kJ/min) & $4 \cdot 63$ & 0.08 & $4 \cdot 75$ & 0.11 & 4.55 & $0 \cdot 10$ & 4.42 & 0.21 \\
\hline
\end{tabular}




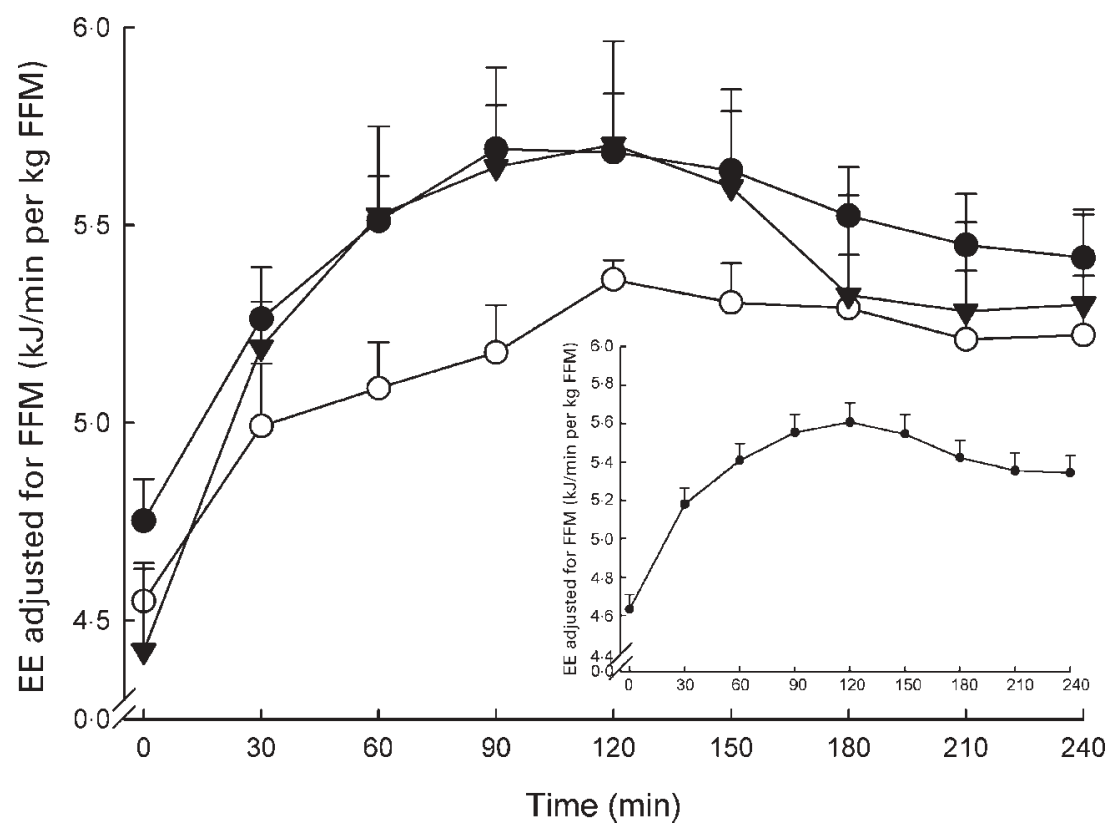

Fig. 1. Energy expenditure (EE) adjusted for fat free mass (FFM; $\mathrm{kg} / \mathrm{min}$ per $\mathrm{kg} F F M)$ for the three genetic variations in the $\beta_{2}-$ adrenoceptor ( -2 -, Gly $16 \mathrm{Gly}$; $-\bigcirc-$, Gly16Arg; $-\mathbf{\nabla}-$, Arg16Arg) before $(t=0)$ and after (30 min intervals), a high carbohydrate meal. The meal was given directly after $t=0$. Values are means with their standard errors represented by vertical bars. The inset shows the results for the whole group.

( $P=0.003$, adjusted $r^{2} 0.323$ ). When the polymorphism groups were entered into the regression model, the dummy variables did not contribute significantly to absDIT $(P>0 \cdot 20)$. Similar results were found for relDIT.

\section{Discussion}

The aim of the present study was to investigate the influence of the codon 16 variants of the $\beta_{2}$-adrenoceptor gene on the thermogenic response to a meal. We hypothesised that subjects with the Arg16Arg polymorphism of the $\beta_{2}$-adrenoceptor would have a lower DIT after the meal than subjects with the Arg16Gly or Gly16Gly polymorphism. Our data do not support this hypothesis. In contrast, there was a higher relDIT and a trend towards a higher absDIT in the Arg16Arg carriers compared with the Gly polymorphism carriers. absDIT was most strongly associated with the adrenaline response to the meal, and an additional independent contribution of the polymorphism could not be demonstrated.

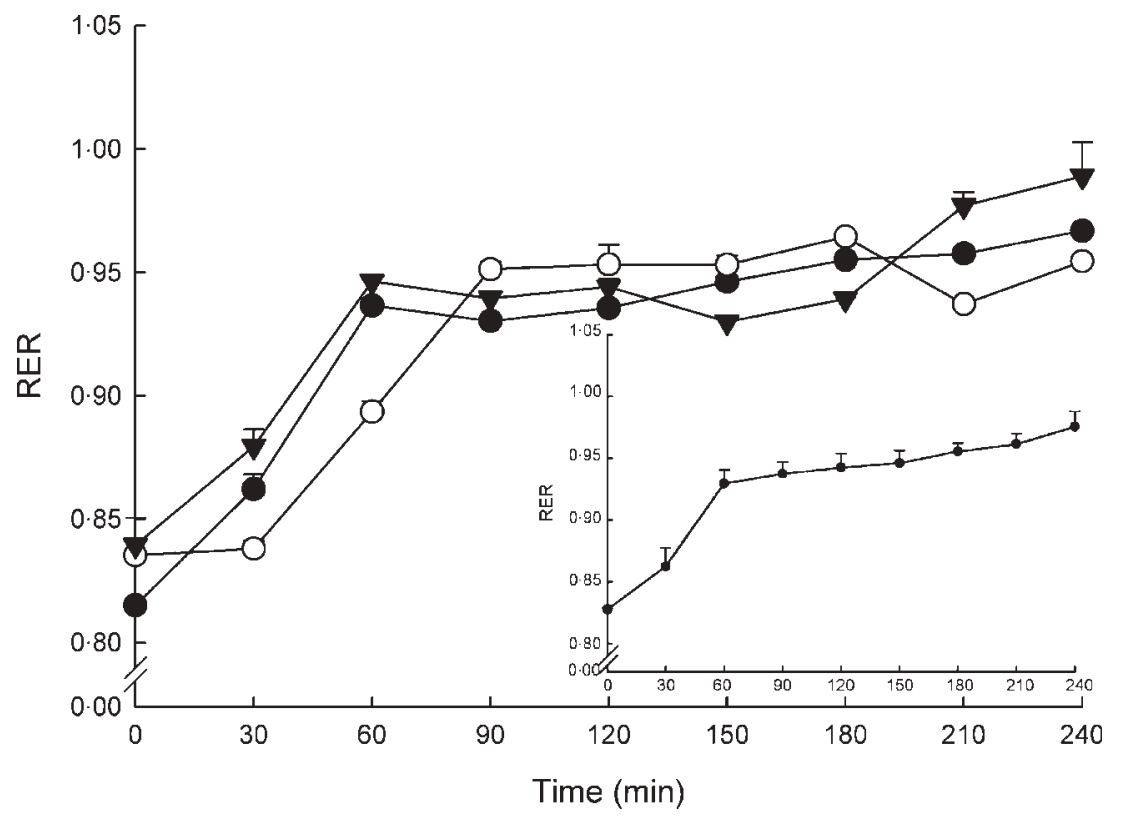

Fig. 2. Respiratory exchange ratio (RER) for the three genetic variations in the $\beta_{2}$-adrenoceptor ( - -, Gly $16 \mathrm{Gly} ;-\bigcirc-\mathrm{Gly} 16 \mathrm{Arg} ;-\mathbf{\nabla}-$, Arg16Arg) before $(t=0)$ and after ( $30 \mathrm{~min}$ intervals) a high carbohydrate meal. Values are means with their standard errors represented by vertical bars. The inset shows the results for the whole group. 

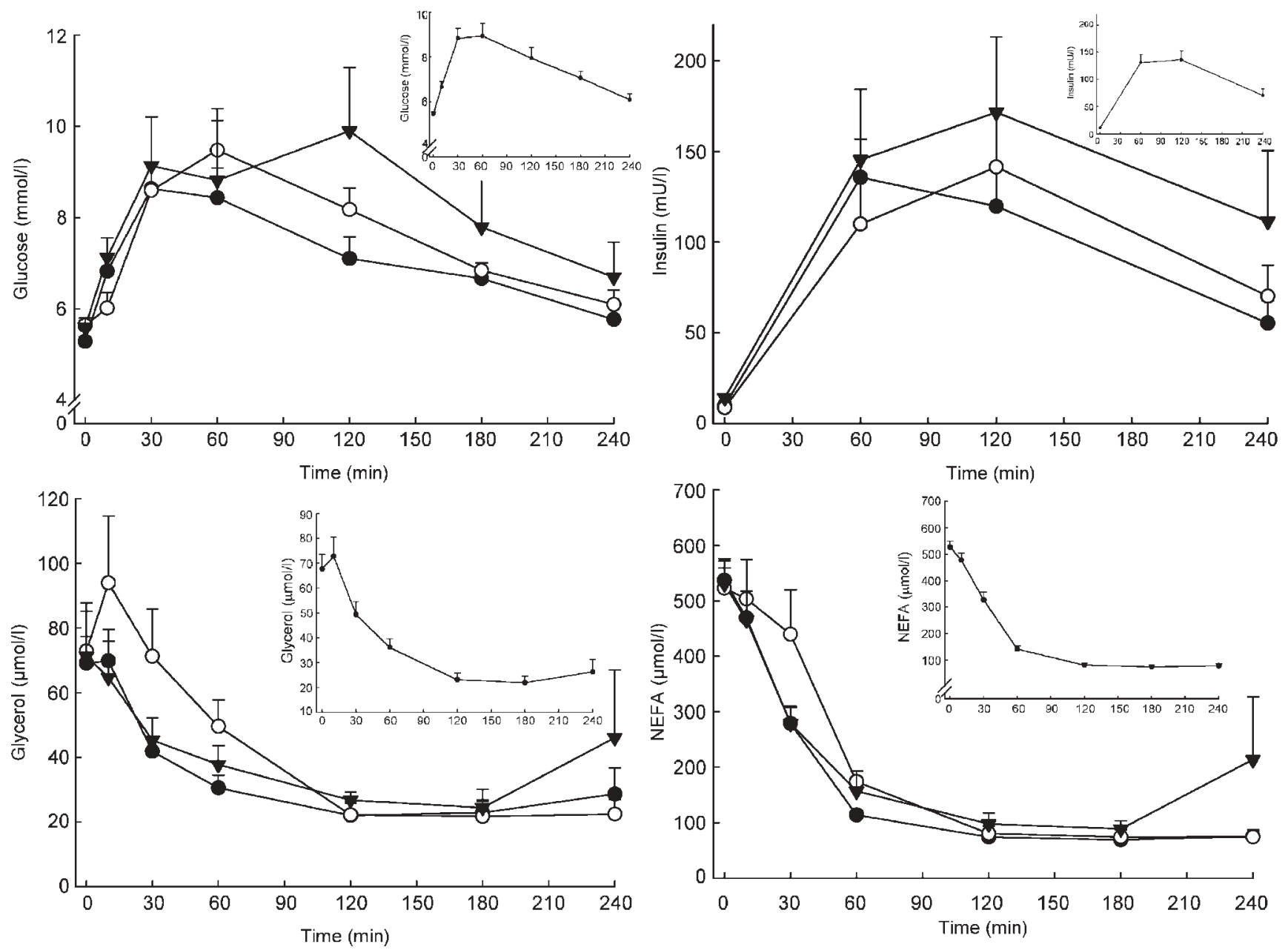

Fig. 3. Plasma glucose, insulin, glycerol and NEFA for the three genetic variations in the $\beta_{2}$-adrenoceptor (-O-, Gly16Gly; $-\bigcirc-$, Gly16Arg; $-\mathbf{\nabla}-$, Arg16Arg), before $(t=0)$ and after $(10,30,60,120,180$ and $240 \mathrm{~min})$ a high carbohydrate meal. Values are means with their standard errors represented by vertical bars.
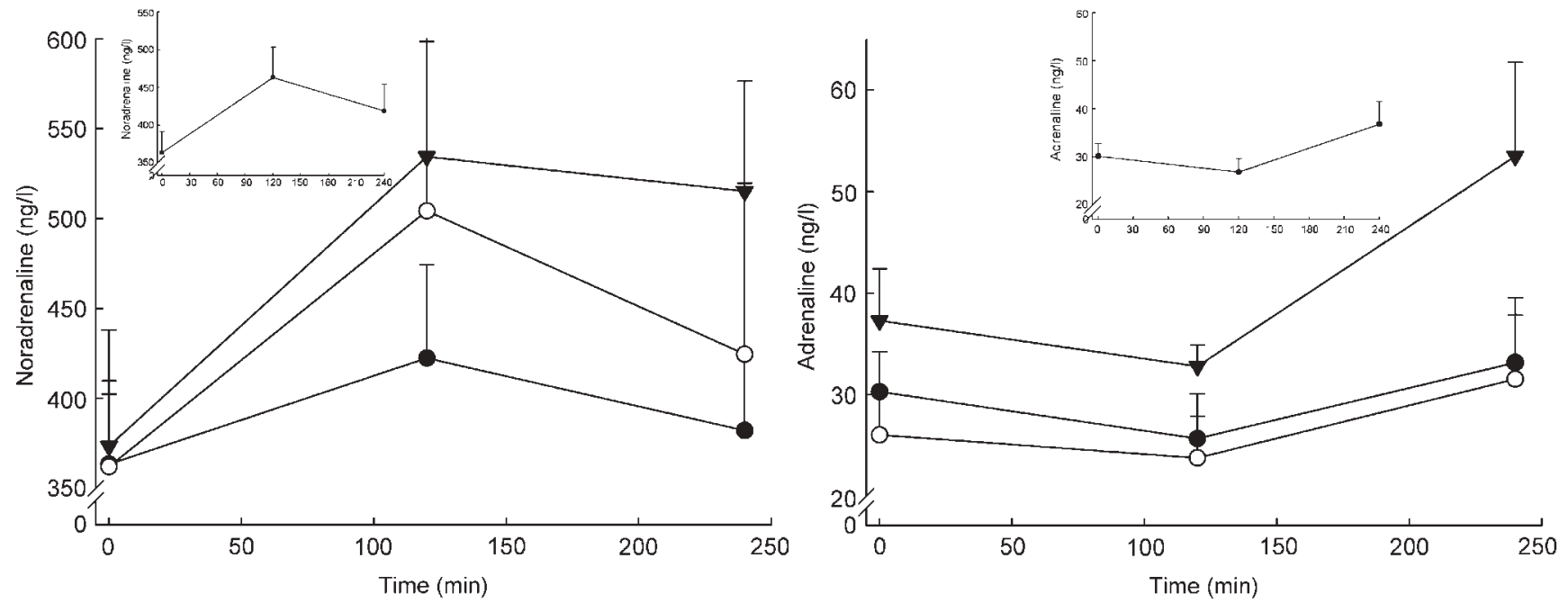

Fig. 4. Plasma nonadrenaline and adrenaline levels for the three genetic variations in the $\beta_{2}$-adrenoceptor ( - -, Gly 16 Gly; $-\bigcirc-$, Gly16Arg; $-\mathbf{\nabla}-$, Arg16Arg), before $(t=0)$ and after (120 min intervals) a high carbohydrate meal. Values are means with their standard errors represented by vertical bars. The insets shows the results for each whole group. 
Table 2. Absolute diet-induced thermogenesis (absDIT) and relative dietinduce thermogenesis (relDIT) in the polymorphism groups, Gly16Gly, Gly16Arg and Arg16Arg

(Values are means with their standard errors)

\begin{tabular}{|c|c|c|c|c|c|c|}
\hline & \multicolumn{2}{|c|}{$\begin{array}{c}\text { Gly } 16 \text { Gly } \\
n 13\end{array}$} & \multicolumn{2}{|c|}{$\begin{array}{c}\text { Gly } 16 \text { Arg } \\
n 6\end{array}$} & \multicolumn{2}{|c|}{$\begin{array}{c}\text { Arg16Arg } \\
n 5\end{array}$} \\
\hline & Mean & SEM & Mean & SEM & Mean & SEM \\
\hline Abs DIT (kJ/4h) & $175 \cdot 1$ & $14 \cdot 6$ & 147.5 & $10 \cdot 8$ & $232 \cdot 2$ & $14 \cdot 3$ \\
\hline Rel DIT (\%/4 h) & $15 \cdot 5$ & 1.5 & 13.5 & $1 \cdot 1$ & $22 \cdot 7$ & $6 \cdot 4$ \\
\hline
\end{tabular}

Meal-induced thermogenesis is partly mediated by increased sympathoadrenal activity (Valensi et al. 1998; Camastra et al. 1999; Schwartz et al. 1999; Lowell \& Bachman, 2003). ß-Adrenoceptor blockade blunts meal-induced thermogenesis, especially between 2 and $4 \mathrm{~h}$ after the meal (Astrup et al. 1989), indicating that the $B$-adrenergic branch of the sympathoadrenal system is involved in this response during this period. In particular, the $\beta_{2^{-}}$ adrenoceptor seems to be important in catecholamine-induced thermogenesis (Nagase et al. 2001). The magnitude of the meal-induced stimulation of the sympathoadrenal system is mainly determined by the size of the meal and its carbohydrate and protein content (Schwartz et al. 1999). Because we wanted to study differences in response to meal-induced stimulation of the $\beta_{2}$-adrenoceptors between subjects with different variants of the $\beta_{2}$-adrenoceptor gene, we tried to optimise the meal-induced $\beta$-adrenergic stimulation by giving a large meal with a high carbohydrate content.

Over the $4 \mathrm{~h}$ post-meal period, the expected increases in EE, respiratory exchange ratio, and glucose and insulin concentrations were found, accompanied by reductions in plasma NEFA and glycerol concentrations (Welle \& Campbell, 1983b; Astrup et al. 1987). Differences in insulin sensitivity have been shown to affect DIT (Camastra et al. 1999). In the present study, however, the homeostasis model assessment index, as a measure of insulin sensitivity, was not correlated with absDIT. This could be due to the fact that the variation in homeostasis model assessment index in our study was relatively small. DIT has also been shown to be impaired in obese compared with lean individuals, although results are not consistent (de Jonge \& Bray, 2002). We did not find a significant correlation between percentage fat and absDIT $(r-0 \cdot 272, P=0 \cdot 199)$, or between BMI and absDIT $(r$ 0.141,

Table 3. Pearson correlations $(r)$ of different variables with absolute diet-induced thermogenesis (absDIT), and corresponding $P$ values.

\begin{tabular}{lcl}
\hline & $r$ & $P$ value \\
\hline Energy content test meal & 0.459 & $0.024^{*}$ \\
AUC glucose & 0.116 & 0.606 \\
AUC insulin & 0.292 & 0.177 \\
AUC NEFA & 0.182 & 0.442 \\
AUC glycerol & -0.142 & 0.528 \\
Baseline plasma noradrenaline & 0.395 & 0.056 \\
Baseline plasma adrenaline & 0.096 & 0.656 \\
AUC noradrenaline & 0.109 & 0.620 \\
AUC adrenaline & 0.595 & $0.003^{*}$ \\
HOMA index & 0.260 & 0.220 \\
Fat percentage & $-0.272 \dagger$ & $0.199 \dagger$ \\
BMI & 0.141 & 0.512
\end{tabular}

AUC, area under the curve; HOMA, homeostasis model assessment. ${ }^{\star} P<0.05 ; \dagger P<0.2$
$P=0.512$ ), but the ranges of percentage fat and BMI in our group were relatively small.

The plasma noradrenaline concentration was increased at 2 and $4 \mathrm{~h}$ after the meal, the plasma adrenaline level only at $4 \mathrm{~h}$. This early response in plasma noradrenaline level and delayed response in plasma adrenaline level has been shown before (Welle \& Campbell 1983a; Astrup et al. 1987). Astrup et al. (1986) suggested that the delayed increase in plasma adrenaline was elicited by the decrease in plasma glucose during this period. The AUC of the post-meal changes in plasma adrenaline was the only parameter that contributed significantly to the variation in DIT $\left(r^{2} 0 \cdot 32\right)$. Because adrenaline has a higher affinity for $\beta_{2}$-adrenoceptors than $\beta_{1}$ - or $\beta_{3}$-adrenoceptors (Hoffmann et al. 2004), the metabolic effects of adrenaline are predominantly mediated by $\beta_{2}$-adrenoceptors. Our data do not support a modulation of the adrenaline-induced thermogenic effect by the codon 16 polymorphism of the $\beta_{2}$-adrenoceptor gene, as hypothesised. There was no evidence for a blunted absDIT in subjects with the Arg16Arg variant of the gene compared with Gly16 polymorphism carriers. Instead, we found a trend towards an increased absDIT in the Arg16Arg group compared with the glycine carriers, and relDIT was significantly higher in the Arg16Arg group. Based on the results of the multiple regression analysis, this difference in DIT was partly explained by a variation in adrenaline response, although we were unable to demonstrate statistically significant differences in adrenaline response between the groups.

Our initial hypothesis of a reduced DIT in Arg16Arg homozygotes was based on several previous findings. The Arg16Arg polymorphism has been associated with a reduced sensitivity to $\beta_{2^{-}}$ adrenoceptor agonist-induced lipolysis in isolated human fat cells (Large et al. 1997; Eriksson et al. 2004). Moreover, in a previous study, we showed that individuals with the Arg16Arg genotype had a blunted thermogenic response to stimulation with the $\beta_{2}$-adrenoceptor agonist salbutamol compared with Gly 16 carriers (Oomen et al. 2005). Both factors might contribute to an increased susceptibility to weight gain and obesity in Arg16Arg carriers. The Arg16 polymorphism has indeed been associated with obesity or obesityrelated phenotypes in many studies (Echwald et al. 1998; Hellstrom et al. 1999; Kortner et al. 1999; Meirhaeghe et al. 1999; Ukkola et al. 2001; van Rossum et al. 2002; Garenc et al. 2003; Gonzalez Sanchez et al. 2003), although there are also studies that do not find this association (Ishiyama-Shigemoto et al. 1999; Hayakawa et al. 2000). The results of this study, however, suggest that even though the Arg 16 variant of the $\beta_{2}$-adrenoceptor may be less sensitive to direct $\beta_{2}$-adrenoceptor stimulation in vitro and in vivo, the thermogenic response to a meal is increased rather than reduced in Arg 16 homozygotes compared with Gly16 carriers.

Whether the lower sensitivity of the $\operatorname{Arg} 16 \operatorname{Arg} \beta_{2}$-adrenoceptor is compensated by a higher level of sympathetic stimulation, or whether a higher level of stimulation induces a reduced responsiveness of the $\beta_{2}$-adrenoceptor, cannot be derived from our data. The latter mechanism seems unlikely in view of the fact that, in vitro, an enhanced agonist-promoted downregulation of the Gly16 receptor compared with the Arg16 receptor is well established (Liggett, 1997). However, the opposite has been demonstrated in vivo for isoprenaline-induced venodilatation, which was insensitive to downregulation in Gly16 homozygotes, whereas those homozygous for Arg 16 showed significant downregulation during the $2 \mathrm{~h}$ isoprenaline infusion (Dishy et al. 2001).

How a reduced sensitivity of the $\beta_{2}$-adrenoceptor could lead to an increased activation of the sympathoadrenal system is not clear from 
our data, but assuming that the adrenaline response is indeed linked to changes in plasma glucose (Astrup et al. 1986), it is conceivable that a reduced glucose output by the liver to compensate for the fall in blood glucose late after the meal would induce a higher adrenaline response. Glucose output by the liver could be compromised by less responsive $\beta_{2}$-adrenoceptors involved in liver glycogenolysis or in reduced gluconeogenesis from glycerol owing to compromised $\beta_{2}$-adrenoceptor-mediated lipolysis.

In conclusion, the present study shows that there is no independent contribution of the codon 16 variant of the $\beta_{2}$-adrenoceptor gene to the thermogenic response after a high-carbohydrate meal, but that this response is positively correlated with the plasma adrenaline response to the meal.

\section{References}

Alberts G, Boomsma F, Man in’t Veld AJ \& Schalekamp MA (1992) Simultaneous determination of catecholamines and dobutamine in human plasma and urine by high-performance liquid chromatography with fluorimetric detection. J Chromatogr 583, 236-240.

Astrup A, Andersen T, Henriksen O, Christensen NJ, Bulow J, Madsen J \& Quaade F (1987) Impaired glucose-induced thermogenesis in skeletal muscle in obesity. The role of the sympathoadrenal system. Int J Obes 11, 51-66.

Astrup A, Bulow J, Christensen NJ, Madsen J \& Quaade F (1986) Facultative thermogenesis induced by carbohydrate: a skeletal muscle component mediated by epinephrine. Am J Physiol 250, E226-E229.

Astrup A, Simonsen L, Bulow J, Madsen J \& Christensen NJ (1989) Epinephrine mediates facultative carbohydrate-induced thermogenesis in human skeletal muscle. Am J Physiol 257, E340-E345.

Bessard T, Schutz Y \& Jequier E (1983) Energy expenditure and postprandial thermogenesis in obese women before and after weight loss. Am $J$ Clin Nutr 38, 680-693.

Camastra S, Bonora E, Del Prato S, Rett K, Weck M \& Ferrannini E (1999) Effect of obesity and insulin resistance on resting and glucose-induced thermogenesis in man. EGIR (European Group for the Study of Insulin Resistance). Int J Obes Relat Metab Disord 23, $1307-1313$.

Chagnon YC, Rankinen T, Snyder EE, Weisnagel SJ, Perusse L \& Bouchard C (2003) The human obesity gene map: the 2002 update. Obes Res 11, 313-367.

de Jonge L \& Bray GA (1997) The thermic effect of food and obesity: a critical review. Obes Res 5, 622-631.

de Jonge L \& Bray GA (2002) The thermic effect of food is reduced in obesity. Nutr Rev 60, 295-297, author reply 299-300.

Dishy V, Sofowora GG, Xie HG, Kim RB, Byrne DW, Stein CM \& Wood AJ (2001) The effect of common polymorphisms of the beta2-adrenergic receptor on agonist-mediated vascular desensitization. $N$ Engl $J$ Med 345, 1030-1035.

Donahoo WT, Levine JA \& Melanson EL (2004) Variability in energy expenditure and its components. Curr Opin Clin Nutr Metab Care 7 , 599-605.

Echwald SM, Sorensen TI, Tybjaerg-Hansen A, Andersen T \& Pedersen O (1998) Gln27Glu variant of the human beta2-adrenoreceptor gene is not associated with early-onset obesity in Danish men. Diabetes 47, $1657-1658$.

Eriksson P, Dahlman I, Ryden M, Hoffstedt J \& Arner P (2004) Relationship between beta-2 adrenoceptor gene haplotypes and adipocyte lipolysis in women. Int J Obes Relat Metab Disord 28, 185-190.

Garenc C, Perusse L, Chagnon YC, et al. (2003) Effects of beta2-adrenergic receptor gene variants on adiposity: the HERITAGE Family Study. Obes Res 11, 612-618.

Gonzalez Sanchez JL, Proenza AM, Martinez Larrad MT, Ramis JM, Fernandez Perez C, Palou A \& Serrano Rios M (2003) The glutamine 27 glutamic acid polymorphism of the beta2-adrenoceptor gene is associated with abdominal obesity and greater risk of impaired glucose tolerance in men but not in women: a population-based study in Spain. Clin Endocrinol (Oxf) 59, 476-481.

Granata GP \& Brandon LJ (2002) The thermic effect of food and obesity: discrepant results and methodological variations. Nutr Rev 60, 223-233.

Harris J \& Benedict F (1919) A Biometric Study of Basal Metabolism in Man. Washington: Carnegie Institute.

Hayakawa T, Nagai Y, Kahara T, Yamashita H, Takamura T, Abe T, Nomura G \& Kobayashi K (2000) Gln27Glu and Arg16Gly polymorphisms of the beta2-adrenergic receptor gene are not associated with obesity in Japanese men. Metabolism 49, 1215-1218.

Hellstrom L, Large V, Reynisdottir S, Wahrenberg H \& Arner P (1999) The different effects of a Gln27Glu beta 2-adrenoceptor gene polymorphism on obesity in males and in females. J Intern Med $\mathbf{2 4 5}$, 253-259.

Hoffmann C, Leitz MR, Oberdorf-Maass S, Lohse MJ \& Klotz KN (2004) Comparative pharmacology of human beta-adrenergic receptor subtypes - characterization of stably transfected receptors in $\mathrm{CHO}$ cells. Naunyn Schmiedebergs Arch Pharmacol 369, 151-159.

Ishiyama-Shigemoto S, Yamada K, Yuan X, Ichikawa F \& Nonaka K (1999) Association of polymorphisms in the beta2-adrenergic receptor gene with obesity, hypertriglyceridaemia, and diabetes mellitus. Diabetologia 42, 98-101.

Kortner B, Wolf A, Wendt D, Beisiegel U \& Evans D (1999) Lack of association between a human beta-2 adrenoceptor gene polymorphism (gln27glu) and morbid obesity. Int J Obes Relat Metab Disord 23, $1099-1100$.

Large V, Hellstrom L, Reynisdottir S, Lonnqvist F, Eriksson P, Lannfelt L \& Arner P (1997) Human beta-2 adrenoceptor gene polymorphisms are highly frequent in obesity and associated with altered adipocyte beta- 2 adrenoceptor function. J Clin Invest 100, 3005-3013.

Liggett SB (1997) Polymorphisms of the beta2-adrenergic receptor and asthma. Am J Respir Crit Care Med 156, S156-S162.

Lowell BB \& Bachman ES (2003) Beta-adrenergic receptors, diet-induced thermogenesis, and obesity. J Biol Chem 278, 29385-29388.

Lukaski HC, Bolonchuk WW, Hall CB \& Siders WA (1986) Validation of tetrapolar bioelectrical impedance method to assess human body composition. J Appl Physiol 60, 1327-1332.

Matthews DR, Hosker JP, Rudenski AS, Naylor BA, Treacher DF \& Turner RC (1985) Homeostasis model assessment: insulin resistance and beta-cell function from fasting plasma glucose and insulin concentrations in man. Diabetologia 28, 412-419.

Meirhaeghe A, Helbecque N, Cottel D \& Amouyel P (1999) Beta2-adrenoceptor gene polymorphism, body weight, and physical activity. Lancet 353, 896.

Nagase I, Yoshida T \& Saito M (2001) Up-regulation of uncoupling proteins by beta-adrenergic stimulation in L6 myotubes. FEBS Lett $\mathbf{4 9 4}$, $175-180$.

Oomen JM, van Rossum CT, Hoebee B, Saris WH \& van Baak MA (2005) $\{\beta\} 2$-Adrenergic receptor polymorphisms and salbutamolstimulated energy expenditure. J Clin Endocrinol Metab 90, 2301-230.

Schoffelen PF, Westerterp KR, Saris WH \& Ten Hoor F (1997) A dualrespiration chamber system with automated calibration. J Appl Physiol 83, 2064-2072.

Schutz Y, Golay A, Felber JP \& Jequier E (1984) Decreased glucoseinduced thermogenesis after weight loss in obese subjects: apredisposing factor for relapse of obesity? Am J Clin Nutr 39, 380-387.

Schwartz MW, Baskin DG, Kaiyala KJ \& Woods SC (1999) Model for the regulation of energy balance and adiposity by the central nervous system. Am J Clin Nutr 69, 584-596.

Tappy L (1996) Thermic effect of food and sympathetic nervous system activity in humans. Reprod Nutr Dev 36, 391-397.

Tappy L (2004) Metabolic consequences of overfeeding in humans. Curr Opin Clin Nutr Metab Care 7, 623-628. 
Ukkola O, Tremblay A \& Bouchard C (2001) Beta-2 adrenergic receptor variants are associated with subcutaneous fat accumulation in response to long-term overfeeding. Int J Obes Relat Metab Disord 25, 1604-1608.

Valensi P, Lormeau B, Dabbech M, Miossec P, Paries J, Dauchy F \& Attali JR (1998) Glucose-induced thermogenesis, inhibition of lipid oxidation rate and autonomic dysfunction in non-diabetic obese women. Int J Obes Relat Metab Disord 22, 494-499.

van Marken Lichtenbelt WD, Westerterp KR, Wouters L \& Luijendijk SC (1994) Validation of bioelectrical-impedance measurements as a method to estimate body-water compartments. Am J Clin Nutr 60, $159-166$. van Rossum CT, Hoebee B, Seidell JC, Bouchard C, van Baak MA, de Groot CP, Chagnon M, de Graaf C \& Saris WH (2002) Genetic factors as predictors of weight gain in young adult Dutch men and women. Int J Obes Relat Metab Disord 26, 517-528.

Weir JB (1949) New methods for calculating metabolic rate with special reference to protein metabolism. Journal of Physiology 109, 1-9.

Welle S \& Campbell RG (1983a) Stimulation of thermogenesis by carbohydrate overfeeding. Evidence against sympathetic nervous system mediation. J Clin Invest 71, 916-925.

Welle SL \& Campbell RG (1983b) Normal thermic effect of glucose in obese women. Am J Clin Nutr 37, 87-92. 